\title{
Aşırı Dijital Oyun Oynama Davranışında Anne Tutumu Ve Benlik
}

\author{
Kontrolünün Etkisi
}

\author{
N. Kübra ORMAN ${ }^{1}$, Osman Tolga ARICAK ${ }^{2}$
}

\begin{abstract}
Özet: $\mathrm{Bu}$ araştırmanın amacı ergenlerin aşırı dijital oyun oynama davranışında anne tutumu ve benlik kontrolünün etkisini incelemektir. Araştırmanın örneklemini Kocaeli'nde bir eğitim kurumunda öğrenim gören dijital oyun oynama düzeylerine göre 30'ar kişilik iki gruba ayrılan 16-18 yaş arası 60 öğrenci oluşturmaktadır. Katılımcılara Kişisel Bilgi Formu, Dijital Oyun Bağımlılı̆̆ Ölçeği, Anne Baba Tutum Ölçeği ve Kısa Öz Kontrol Ölçeği uygulanmıştır. Araştırma edilen bulgulara göre aşırı dijital oyun oynayan grupta en yüksek anne tutumu puanı "Koruyucu Anne Tutumu" puanı ve "Otoriter Anne Tutumu” puanı, kontrol grubunun en yüksek anne tutumu puanı "Demokratik Anne Tutumu" puanı olarak belirlenmiştir. Aşırı dijital oyun oynayan grubun benlik kontrolü puanı ile kontrol grubunun benlik kontrolü puanı arasında kontrol grubu lehine anlamlı bir farklılık olduğu görülmüştür. Aynı veriler doğrultusunda iki grup arasında yaş ortalaması ve bağımlılık arasında anlamlı bir farklılık olduğu ortaya çıkmıştır. Cinsiyetler arasındaki fark incelendiğinde ise aşırı dijital oyun oynayan grupta erkek sayısının anlamlı olarak fazla olduğu saptanmıştır.
\end{abstract}

Anahtar kelimeler: Aşırı Dijital Oyun Oynama, Anne Tutumu, Benlik Kontrolü.

\section{The Impact Of Mother's Attitude And Self-Control On Excessive Digital Gaming Behaviour}

Abstract: The aim of this study is to elucidate the impact of mother's attitude and self-control on excessive digital gaming behaviour of adolescents. The sample was consisted of 60 students (between 16-18) who were studying in a high school in Kocaeli. According to the level of digital gaming behaviour, participants were divided into two groups. Both groups had 30 participants. We administered the sociodemographic data form, Digital Game Addiction Scale, Parental Attitude Scale (MAPAS) and Brief Self-Control Scale. According to the results of the study, the highest MAPAS scores of excessive digital gaming group were found "protective mother attitude" and "authoritative mother attitude". The highest score of "democratic mother attitude" were found in the control group. There was a significant difference between the self control scores in two goups. The control group had higher self-control scores. Moreover, there was a significant difference between two groups in terms of ages and addiction. When it comes to relationship between gender and excessive digital game playing, the male participants were significantly higher in the excessive digital gaming group.

Keywords: Excessive Digital Gaming, Mother Attitude, Self Control.

\footnotetext{
${ }^{1}$ Uzm. Psk., Türkiye Yeşilay Cemiyeti, Yeşilay Danışmanlık Merkezi (YEDAM),

${ }^{2}$ Prof. Dr., Hasan Kalyoncu Üniversitesi, İktisadi İdari ve Sosyal Bilimler Fakültesi, Psikoloji Bölümü

Address of correspondence/ Yazışma adresi: ${ }^{1}$ Uzm. Psk., Türkiye Yeşilay Cemiyeti, Yeşilay Danışmanlık Merkezi (YEDAM), E-mail: kubra.solmaz@yesilay.org.tr
}

Date of Received/Geliş Tarihi: 28.10.2019, Date of Revision/Düzeltme Tarihi: 02.11.2019, Date of Acceptance/Kabul Tarihi: 07.11.2019

Citing/ Referans Gösterimi: Orman, N.K., Arıcak, O.T. (2019). Aşırı Dijital Oyun Oynama Davranışında Anne Tutumu Ve Benlik Kontrolünün Etkisi, 1(Özel Sayl.1): 40-42 doi:10.35365/ctjpp.19.special1.11 


\section{Giriş}

Her geçen yıl çeşitlenerek artan davranışsal bağımlılıklar 21.yüzyılın problemi haline gelmektedir. Davranışsal bağımlılık türlerinden; internet bağımlılığının; alt kategorilerinden biri olarak tanımlayabileceğimiz oyun bağımlılığı; son dönemde çocukların, ergenlerin ve hatta yetişkinlerin hayatındaki sorunlarda birisidir. İnternet kullanımı yașı gün geçtikçe düşmektedir. Çocuk ve adolesan dönemindeki davranışların ve yetişkin evreye geldiği zaman ortaya çıkan bağımlılıkların çoğu zaman yetiştiği ailenin dinamiğine, karar ve denetime bağlı olarak kendini göstermekte olduğu düşünülmektedir. Annenin ise birincil bakım veren kişi olarak etkinliği göz ardı edilmemesi gerekebilir. Bu mesele yalnızca çevresel bir sorun da değildir. Kişinin kendi öz kontrolünü sağlama yeteneği, dürtüsel eylemleri önleme becerileri de bağımlılıkları önlemeye ve bağımlılıkla mücadeleye yardımcı olan diğer içsel mekanizmalardır. Bu araştırma ergenlerde oyun bağımlılığının yaygınlaşma ve aşırı kullanıma devam etme nedenleriyle ilgili çalışmalara katk1 sağlamak için gerçekleştirilmiştir. Araştırmada ergenlerin dijital oyun oynamasında anne tutumlarının, benlik kontrolünün ve cinsiyetin etkisi incelenmiştir.

\section{Yöntem}

Araştırmanın evrenini Kocaeli'nde bir eğitim kurumunda öğrenim gören 16-18 yaş aras1 60 öğrenci oluşturmaktadır. Öğrenciler dijital oyun oynama düzeylerine göre iki gruba ayrılmış 60 öğrenci arasından, aşırı dijital oyun oynayan grup ile az oynayan ya da hiç oynamayan (kontrol grubu) öğrenciler olmak üzere her bir grup için 30'ar öğrenci seçilmiştir. Burada dağılımın normale yaklaşması için en az 30 öğrencinin alınması kararlaştırılmıştır. Araştırma deseni nedenselkarşılaştırma türünde olduğu için büyük örneklem seçme yoluna gidilmemiştir. Onayı alınan katılımcılara uygulama formları dağıtılmışıı. Araştırmada uygulanacak form ve ölçeklerde de yazılı olarak araştırma amacıyla ve ne amaçla kullanılacağıyla ilgili bilgilere yer verilmiştir. Araştırmada katılımcılara araştırmacı tarafından geliştirilen Kişisel Bilgi Formu, dijital oyun bağımlılığının ölçülmesi için Lemmens ve arkadaşları (2009) tarafindan geliştirilen Irmak ve Erdoğan (2015) tarafindan Türkçeye uyarlanan Dijital Oyun Bağımlılığı Ölçeği (DOP-7) uygulanmıştır. Anne tutumlarının değerlendirilmesi için Kuzgun (1972) tarafindan geliştirilen Ana Baba Tutumları Ölçeği (ABTÖ) kullanılmıştır. Benlik kontrolü ölçümü için ise Tangney, Baumeister ve Boone (2004) tarafindan geliştirilen Nebioglu, Konuk, Akbaba ve Eroglu (2012) tarafindan Türkçe'ye uyarlanan Kısa Öz-Kontrol Ölçeği (KÖKÖ) uygulanmıştır.

Çalışmada kullanılan veri toplama araçlarının uygulanması sonrasında bütün cevap kâğıtları kontrol edilmiştir. Eksik doldurulan form ve ölçekler değerlendirmenin dışında tutulmuştur.

\section{Sonuçlar}

Araştırmadan edilen bulgulara göre aşırı dijital oyun oynayan grupta en yüksek anne tutumu puanı "Koruyucu Anne Tutumu" puanı, kontrol grubunun en yüksek anne tutumu puan1 "Demokratik Anne Tutumu" puanı olarak belirlenmiştir. En yüksek "Otoriter Anne Tutumu” puan dağılımı aşırı dijital oyun oynayan gruptan alınan verilerde saptanmıştır.

Tablo 1. İki Grupta Benlik Kontrolü Puanlarının Dijital Oyun Bağımlılığı Puanına Göre Dağılımı

\begin{tabular}{ll|r|r|r}
\hline & \multicolumn{2}{c}{$\begin{array}{c}\text { Așırı Dijital Oyun Oynayan } \\
\text { Grup }\end{array}$} & Kontrol Grubu & \multicolumn{2}{c}{ Toplam } \\
\hline Dijital Oyun Oynama Puanı & Ortalama & 23,5 & 10,6 & 17,0 \\
\cline { 2 - 6 } & $\mathrm{N}$ & 30,0 & 30,0 & 60,0 \\
\cline { 2 - 6 } & Ss & 4,1 & 4,1 & 7,5 \\
\hline Benlik Kontrol Puan1 & Ortalama & 34,5 & 38,2 & 36,4 \\
\cline { 2 - 6 } & $\mathrm{N}$ & 30,0 & 30,0 & 60,0 \\
\cline { 2 - 6 } & Ss & 3,8 & 4,9 & 4,7 \\
\hline
\end{tabular}

Tablo 1. incelendiğinde aşırı dijital oyun oynayan grubun benlik kontrolü puan ortalaması 34.5, kontrol grubunun benlik kontrolü puan ortalaması 38.2 olarak saptanmıştır.

Tablo 2. Aşırı Dijital Oyun Oynamayan Grup ve Kontrol Grubunun Benlik Kontrolü Sonuçlarının Karşılaştırılması

\begin{tabular}{|c|c|c|c|c|c|}
\hline & Grup & $\mathrm{n}$ & Ortalama & ss & Ortalamanın SH \\
\hline \multirow[t]{2}{*}{ Benlik Kontrolü Puanı } & Aşırı Oyun Oynayan & 30 & 34,53 & 3,812 & ,696 \\
\hline & Kontrol & 30 & 38,17 & 4,907 & ,896 \\
\hline
\end{tabular}

Test ortalamalarına bakıldığında aşırı dijital oyun oynayan grubun benlik kontrol ortalamasının $(\square=34.53)$ kontrol grubunun benlik kontrol puan ortalamasindan ( $\square=38.17$ ) düşük olduğu görülmektedir.
Cinsiyetler arası farka bakıldığında ise aşırı oyun oynayan grubun $\% 93$ 'ünü $(n=28)$ erkekler, $\% 7$ 'sini $(n=2)$ kızlar oluştururken, kontrol grubunun \%47'sini $(n=14)$ erkekler, \%53'ünü (n=16) kızlar oluşturmaktadır. 


\section{Tartışma}

Anne tutumu puanları incelendiğinde daha büyük bir örneklemde de aynı bulgular edinilmiştir (Eni, 2017). Çocuğun psiko-sosyal gelişimini en olumlu şekilde sağlayan ebeveyn tutumu demokratik tutum iken, en olumsuz etkileyen tutum otoriteye dönük, reddedici, ilgisiz ve aşırı koruyucu tutumlardır (Kuzgun ve Eldeleklioğlu, 1999). Bu araştırmadan edilen diğer sonuca göre iki grup arasında benlik kontrolü ve oyun oynama davranışı açısından da az da olsa anlamlı bir fark vardır. Araştırmanın bu bulguları Abedini ve arkadaşlarının (2012) yaptığı araştırmadan elde edilen bulgular ile de örtüşmektedir. Araştırmaya göre otoriter ve koruyucu anne tutumu sergileyen anneler çocuklarına daha az sorumluluk yüklemekte ve bu nedenle annelerin çocukları benlik kontrolünü daha az sağlamaktadır.
Kontrol mekanizması güçü olmayan çocuklar davranışlarını kontrol edemediği için daha sık dijital (video) oyun oynamaktadır. Anne tutumu, benlik kontrolü ve oyun oynama davranışı açısından bir etkileşim olduğu görülmektedir.

$\mathrm{Bu}$ çalıșmada verilerin sadece özel bir öğretim kurumundan toplanması ve örneklemin küçük olması bir diğer önemli sınırlılık olarak görülmüştür. Sadece 16-18 yaş arası bireylerle çalışılmıştır. Yine sadece algılanan anne tutumunun ele alınmış olması da bu çalışmanın sınırlılıklarından biridir. Bundan sonraki çalışmaların farklı illerde ve farklı ögretim kurumlarında daha büyük örneklemler üzerinde hem anne hem de baba tutumlarının dâhil edildiği daha geniş yaş grupları üzerinde gerçekleştirilmesi önerilmektedir.

\section{Kaynaklar}

Abedini, Y., Zamani, B. E., Kheradmand, A., \& Rajabizadeh, G. (2012). Impacts of mothers' occupation status and parenting styles on levels of self-control, addiction to computer games, and educational progress of adolescents. Addiction \& health, 4(3-4), 102 .

Eni, B. (2017). Lise öğrencilerinin dijital oyun bağımlıllğg ve algiladıkları ebeveyn tutumlarının değerlendirilmesi (Yüksek lisans tezi, Haliç Üniversitesi, Sosyal Bilimler Enstitüsü, İstanbul). https://tez.yok.gov.tr/UlusalTezMerkezi/ adresinden edinilmiş̧ir
Irmak, A. Y., \& Erdoğan, S. (2015). Validity and reliability of the Turkish version of the digital game addiction scale. Anatolian Journal of Psychiatry, 16(Special Issue.1), 1018.

Kuzgun, Y. ve Eldeleklioğlu, J. (1999). Ana baba tutum ölçeğinin geliștirilmesi. Uludağ Üniversitesi Eğitim Fakültesi Dergisi, 12(1), 69-77.

Nebioglu, M., Konuk, N., Akbaba, S., \& Eroglu, Y. (2012). The investigation of validity and reliability of the Turkish version of the Brief Self-Control Scale. Klinik Psikofarmakoloji BülteniBulletin of Clinical Psychopharmacology, 22(4), 340-351. 